\title{
Mesoscale Spatial Variability of Linear Trend of Precipitation Statistics in Korean Peninsula
}

\author{
Jaehyeon Lee, ${ }^{1}$ Jaehyun Ahn, ${ }^{2}$ Eunsoo Choi, ${ }^{1}$ and Dongkyun Kim ${ }^{1}$ \\ ${ }^{1}$ Department of Civil Engineering, Hongik University, Seoul 04066, Republic of Korea \\ ${ }^{2}$ Department of Civil and Architectural Engineering, Seokyeong University, Seoul, Republic of Korea \\ Correspondence should be addressed to Dongkyun Kim; kim.dongkyun@hongik.ac.kr
}

Received 4 November 2015; Revised 19 April 2016; Accepted 5 May 2016

Academic Editor: Jan Friesen

Copyright (c) 2016 Jaehyeon Lee et al. This is an open access article distributed under the Creative Commons Attribution License, which permits unrestricted use, distribution, and reproduction in any medium, provided the original work is properly cited.

\begin{abstract}
This study analyzed the spatial variability of the linear trend of the precipitation mean, variance, lag-1 autocorrelation coefficient, and probability of dryness (PD) based on the precipitation data between 1981 and 2015 observed at 65 rain gages located across Korean Peninsula. While the result of the Mann-Kendall test based on the yearly statistics showed no temporal trend at most of the gage locations, the same test based on the 20-yearly statistics showed that statistically significant temporal trend exists at $54 \%$ (mean), 60\% (variance), 61\% (autocorrelation), and 61\% (PD) among the total 65 rain gages. In addition, this study produced the map of the linear trend of the precipitation statistics. The map showed a clear regional and seasonal tendency implying that the impact of the climate change varies significantly within Korea. The variogram analysis revealed that the approximate characteristic scale of linear trend of hourly and daily precipitation statistics ranges between $50 \mathrm{~km}$ and $200 \mathrm{~km}$ and between $100 \mathrm{~km}$ and $250 \mathrm{~km}$, respectively. This characteristic scale is significantly smaller than the spatial scale of atmospheric circulation, which suggests that future water resources management plans of Korea should consider this mesoscale variability that otherwise can be missed if it is based only on the GCM simulation results.
\end{abstract}

\section{Introduction}

Evidences of global climate change are constantly reported. The global mean temperature has increased by $0.8^{\circ} \mathrm{C}$ over the last 100 years [1]. The decade from 2000 to 2010 was reported to be the warmest decade, and 2010 along with 2005 was recorded as the warmest year in the weather observation history. The rise of temperature and its unbalanced spatiotemporal distribution accelerated the atmospheric and hydrologic circulation [2]. The Intergovernmental Panel on Climate Change (IPCC) indicated that total precipitation, return frequency, and the amount of extreme precipitation have increased constantly, based on the results of simulation and analyses of past data. In particular, the IPCC [3] highlighted the following remarks regarding the changes of precipitation pattern of mid-latitude regions of northern hemisphere including Korean Peninsula over the next 100 years: (1) extreme precipitation and the occurrence frequency will increase in middle-latitude and tropical region and
(2) the duration of precipitation during the monsoon season, including typhoons, will increase.

The validity of this future projection regarding the precipitation pattern of Korean Peninsula is well supported by numerous previous studies which examined the trend of the past precipitation observation. There is a general consensus among these studies that Korean Peninsula has a strong trend of increasing average precipitation due to the increase of heavy precipitation amount and frequency. Chung and Yoon [4] found that there has been an increase of $182 \mathrm{~mm}$ of annual precipitation over Korean Peninsula from 1906 to 1997. Regarding this change, Kim et al. [5] indicated that the precipitation increase is due to the regime shift of large-scale atmospheric circulation feature of East Asia that is influenced by southward shift of the summertime East Asian subtropical westerly jet and the westward expansion of the North Pacific subtropical high [6-9]. Chung et al. [10] indicated that, due to this regime shift, the quasi-stationary polar front (so-called "Changma front" in Korean), which causes a significant 
portion of precipitation while staying over Korean Peninsula, has shifted northward toward northern China, so the original consistent and long-lasting frontal precipitation pattern has been replaced with scattered convective showers with greater intensity on a local scale in July and August. Ho et al. [11] found that the period of 1978-2001 has shorter intermodal rain spell period (early July-early September) compared to the period of 1954-1977 (early July to mid-late August) because of the enhanced heavy precipitation events $\left(>30 \mathrm{~mm} \mathrm{day}^{-1}\right)$. Kim et al. [5] attributed a good portion of the precipitation increment to the interdecadal change of the typhoon landfall on Korean Peninsula. Kim et al. [12] pointed out that Korean Peninsula experienced the abrupt increase in the intensity and frequency of heavy precipitation after 1997 according to the result of the Bayesian change point analysis.

While most of these studies investigated the change of precipitation characteristics by analyzing the time series at the selected set of individual rain gages, some studies focus on the spatial pattern of this change. Osborn et al. [13] showed that the temporal trend of daily precipitation of the UK has spatial variation; Frei and Schär [14] suggested a binomial statistical framework for trend analysis to detect the temporal trend in rare extreme precipitation events in Switzerland. They discovered that the trend is highly influenced by orography of Alpine Region; Wang and Zhou [15] showed that the temporal trend of extreme precipitation events has spatial tendency associated with the changes in large-scale atmospheric circulation; Brunetti et al. [16] showed that the degree of temporal trend of precipitation of Italy has spatial variation due to the shift of atmospheric circulation pattern and orography; Chang and Kwon [17] showed that the temporal trend of summer precipitation of Korea is the greatest in northern and central western part of South Korea. Kunkel et al. [18] showed that the increasing trend of heavy precipitation in the coterminous United Sates is the strongest in Northeast and East-North-Central United States; Roy and Rouault [19] showed that the increasing trend of summer precipitation in South Africa is the greatest along the southeastern and western coastal area. They indicated that orography and sea surface temperature rise can be the cause of this regionality.

The spatial variation of the temporal trend of precipitation can occur not only at global scale [20-22] due to the change of atmospheric circulation pattern but also at regional scale [23-25] mostly due to terrain [26]. For regions like Korean Peninsula where the spatial and seasonal variability of precipitation is significant due to various precipitation generation mechanisms, thorough understanding of the change of precipitation characteristics due to climate change at a fine spatial scale is particularly important because it can provide crucial information for developing the water resources plans precisely tailored to local governments.

For this reason, this study investigated the spatial variability of linear trend of precipitation in Korean Peninsula. To achieve this purpose, this study calculated the linear trend of various precipitation statistics at 65 precipitation observation stations across Korean Peninsula and produced the maps of the linear trend of each precipitation statistic for each calendar month. This analysis is particularly meaningful because few previous studies investigating the impact of climate change on Korean Peninsula specifically focus on its spatial variability occurring at the spatial scale of $\sim 100$ kilometers (or mesoscale). The result of the analysis shows that the linear trend of precipitation of all seasons of Korea has clear spatial pattern.

In addition, this study verifies whether the various precipitation statistics have statistically significant temporal trend using the Mann-Kendall test. The result indicates that when the statistics are calculated for each individual year, no statistically significant temporal trend is detected. However, when the statistics are calculated for the 20-year moving window, statistically significant temporal trend is detected at approximately $50 \%$ to $90 \%$ of the observation gages depending on the types of statistics and the season.

\section{Methodology}

2.1. Data Description. This study selected 65 precipitation observation stations operated by the Korea Meteorological Administration (Figure 1). All precipitation gages have the record length longer than 30 years. The precipitation data has a temporal resolution of 1 hour, and the precipitation record considered in this study starts from 1973 and ends at December 2015. This study analyzed only the data recorded on and after 1981 because precipitation data is available at all 65 gages with minimal missing record during this period.

2.2. Calculation of Precipitation Statistics and Linear Trend. The precipitation statistics analyzed in this study are the mean, variance, lag-1 autocorrelation coefficients, and the probability of dryness (proportion of nonrainy period to the entire period). Each statistic was calculated for each calendar month and also at 1-, 3-, 6-, 12-, and 24-hourly accumulation levels. In addition, the statistics of the precipitation time series contained in the 20-year moving window were calculated to figure out the trend of long-term precipitation characteristics. Here, for convenience, we call the precipitation statistics based on the 20-year moving window as 20-yearly statistics. As a result, each rain gage has 480 (4 different types of statistics $\times 12$ calendar months $\times 5$ accumulation levels $\times 2$ window sizes) different time series of precipitation statistics. Figure 2 shows the time series of the 1-hour mean precipitation observed in July at Seoul observation station. Dots are the yearly mean values, and crosses are the 20 -yearly mean values. Rectangular box is an example of 20 -year moving window.

After the statistics are calculated for different months, accumulation levels, and moving windows to develop as a time series as shown in Figure 2, linear regression analysis was performed to obtain the slope of the least square fit regression line, which was assumed to represent the linear trend of each precipitation statistic. Solid and dotted lines in Figure 2 are the linear regression lines of the yearly precipitation mean and the 20-year moving window precipitation mean.

\subsection{Preparation of a Map of the Linear Trend of Precipitation} Statistics. This study produced maps of the linear trend in order to identify the regional characteristics of the linear 


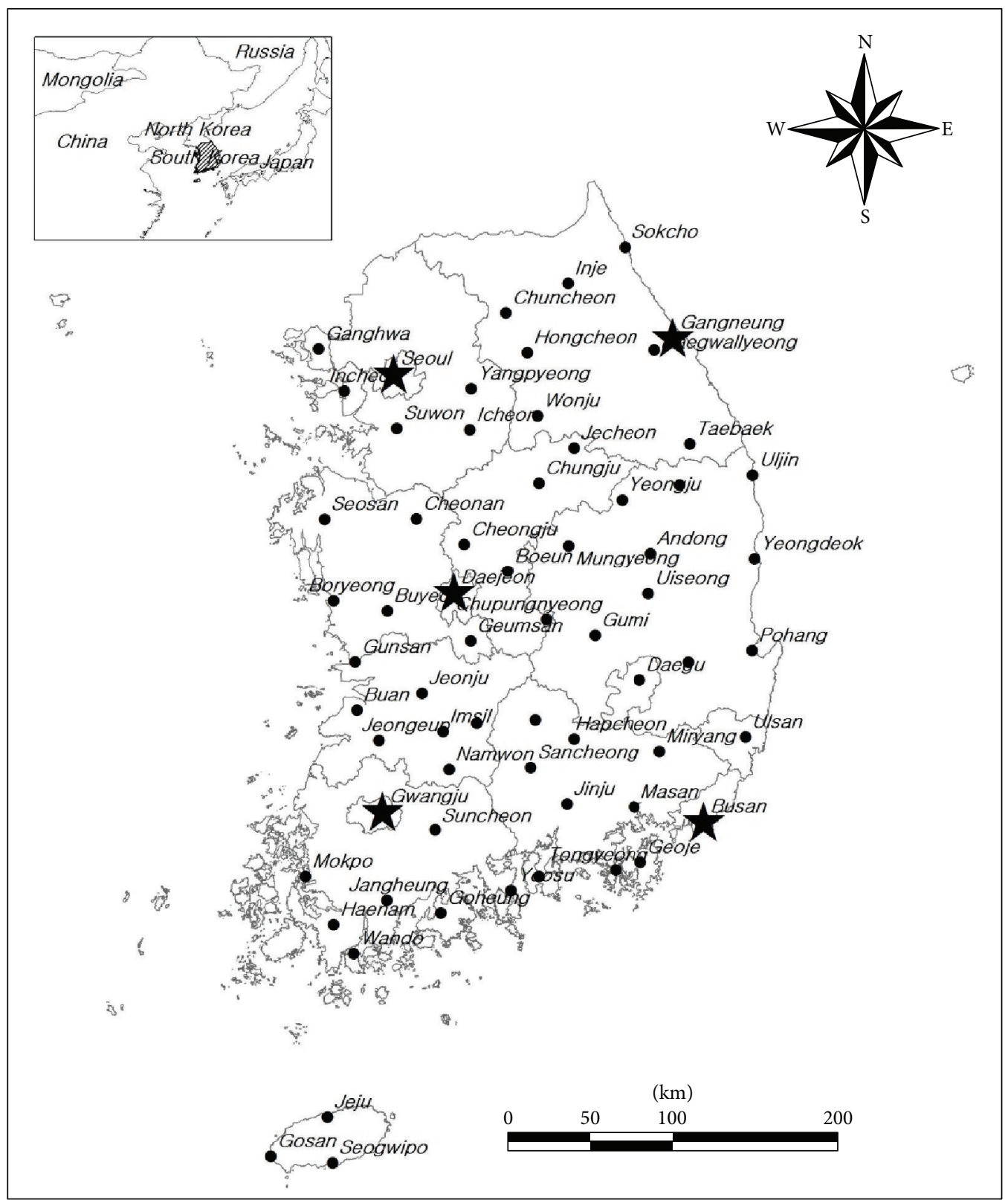

FIgURE 1: Location of the 65 precipitation gages in Korean Peninsula operated by the Korea Meteorological Administration.

trend of each precipitation statistic. Ordinary Kriging geospatial interpolation technique was used to develop the map. In this process, the model variogram of each precipitation statistic was assumed to have the stable model type and the parameters of the model variogram were estimated such that the residual between the sample and model variogram is minimized.

2.4. Mann-Kendall Test. This study performed the MannKendall test to see if there is a statistically significant temporal trend in the calculated precipitation statistics. The test statistic $S$ of the Mann-Kendall test is calculated as follows:

$$
S=\sum_{k=1}^{n-1} \sum_{i=k+1}^{n} \operatorname{sign}\left(x_{i}-x_{k}\right),
$$

where $x_{i}$ is the $i$ th observation in the time series of $x$ and $n$ is the number of observations. The sign operator has the value of 1,0 , and -1 when the value inside the parenthesis is positive, zero, and negative, respectively. When this test statistic is above (or below) a given value which is determined by the sample size $n$ and significance level, the null hypothesis stating that the time series does not have any temporal trend is rejected. This study adopted the significance level of 5\%.

\section{Result}

3.1. Linear Trend of the Precipitation Statistics. Figures 3 and 4 show the yearly variation of the precipitation statistics at 1hour accumulation level for the month of April, July, August, 


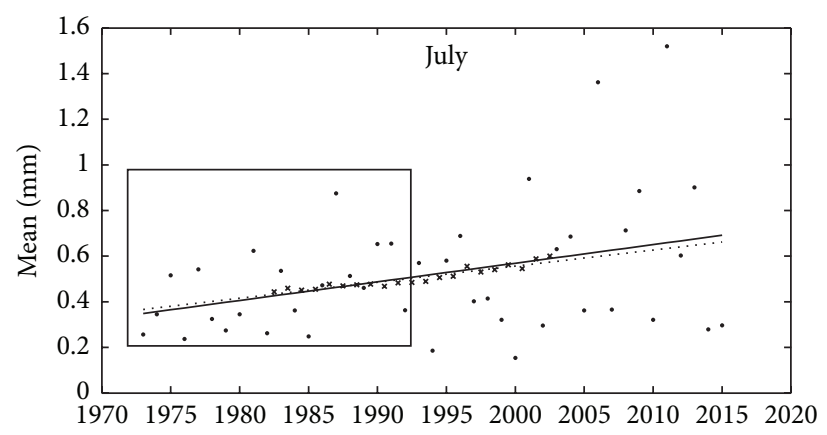

(yr)

$$
\begin{array}{lll}
\text { - Yearly } & \times \quad 20 \text {-yearly } \\
- & y=0.008 x-16 \quad \cdots \cdots & y=0.007 x-14
\end{array}
$$

Figure 2: Time series of the 1-hour mean precipitation observed in July at Seoul observation station. Dots are the yearly mean values, and crosses are the 20-yearly mean values. Solid and dotted lines are the least square fit linear regression line of the yearly and 20 -yearly mean values, respectively.

and December observed at Seoul station shown in Figure 1. Figure 3 shows the graphs of the precipitation mean and variance, and Figure 4 shows the graphs of the lag- 1 autocorrelation $(\mathrm{ACl})$ and probability of dryness $(\mathrm{PD})$. Dots are the statistics corresponding to yearly statistics, and crosses are the 20-yearly statistics. Solid and dotted lines are the least square fit linear regression line of the dots and crosses, respectively.

The precipitation mean and variance had a clear increasing trend for summer season (July and August) and showed a decreasing trend for April and December. The precipitation $\mathrm{ACl}$ showed a decreasing trend for April and increasing trend for July, August, and December. The precipitation PD showed an increasing trend for April and December and a decreasing trend for July and August. However, its trend was not as clear as that of precipitation mean and variance. The increasing precipitation mean and variance and decreasing PD mean that more precipitation occurs over shorter period of time in Seoul during the majority of the summer season (July and August) compared to the past. The opposite trend (less precipitation over longer period of time) was observed for the month of April and December. These results agree with the finding of Kim et al. [27], which discussed the precipitation polarization phenomenon between wet and dry season of Korean Peninsula and its adverse impact on water resources management.

Figure 5 shows the seasonal variation of the linear trend of the 20 -yearly precipitation statistics at hourly accumulation level at the five major cities located across the Korean Peninsula shown in Figure 1 (star marks). In general, the linear trend of precipitation mean and variance has clear positive values for summer and early fall season (July through September) and the values close to zero for the remaining calendar months. The linear trend of precipitation PD has clear positive values for the dry season (February to April and October to December). Also, the clear negative values are apparent for the month of August. The linear trend of AC1 does not have any clear seasonal trend. The seasonal pattern of linear trend of Busan was different from that of the remaining 4 cities. This seems to be because Busan is located at the southern coastal edge of Korean Peninsula at which the mechanisms of precipitation generation can be affected by different factors compared to the inland cities. These results suggest that the seasonal precipitation polarization phenomenon is occurring across Korean Peninsula not restricted to a specific local area.

\subsection{Statistical Test on the Precipitation Statistics Stationarity.} Figure 6 shows the percentage of the gages among all 65 gages shown in Figure 1 at which stationarity assumption of MannKendall test is rejected. At the gages where the null hypothesis of the test is rejected, the temporal trend of the precipitation statistics is so significant that it cannot be ignored. Figures 6(a) and 6(b) show the result of the tests performed on the precipitation time series with 1-hour and 24-hour accumulation levels, respectively. For each plot, the values corresponding to yearly and 20-yearly precipitation statistics are shown. The temporal trend was not significant for the yearly precipitation statistics for both 1-hour and 24-hour accumulation levels having the rejection percentage ranging between $0 \%$ and $37 \%$. However, the temporal trend became dramatically apparent for most of the 20-yearly precipitation statistics having the rejection percentage ranging between $28 \%$ and $88 \%$.

The key to understand this irony of different test result between the yearly and 20-yearly statistics is the characteristics of Mann-Kendall test. As shown in (1), the Mann-Kendall test statistics are rather based on the binary information on whether one value in a time series is greater than another than the actual magnitude of the difference between the two values in the time series. In the meantime, the influence of the climate change on the precipitation in Korean Peninsular is characterized by frequent occurrence of extreme precipitation event. For this reason, the Mann-Kendall test result on yearly precipitation statistics cannot reflect the magnitude of the extreme precipitation because the test treats the yearly 

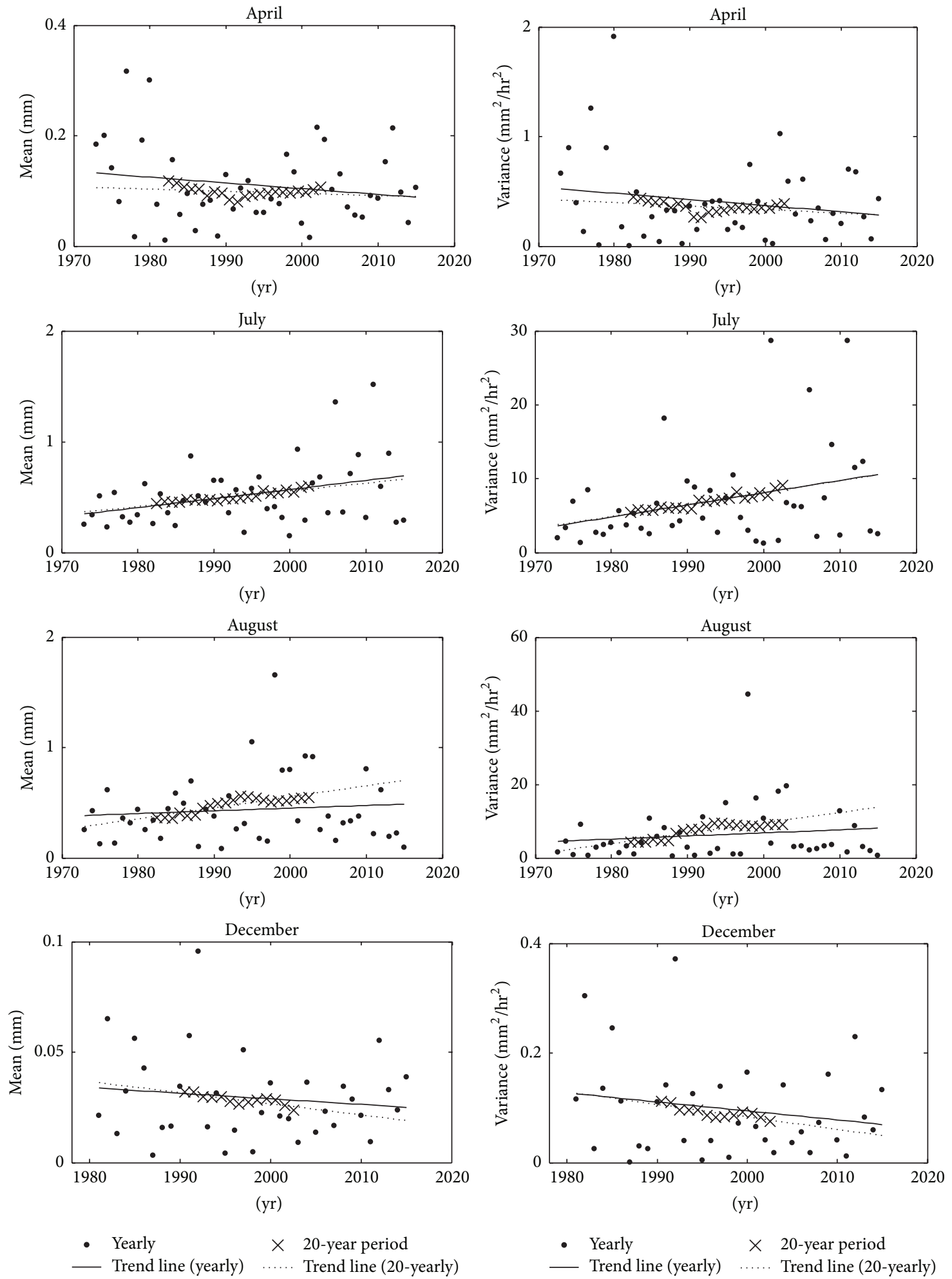

(yr)

- Yearly
- Trend line (yearly)

$\times \quad 20$-year period Trend line (20-yearly)

FIGURE 3: Temporal variation of yearly (dots) and 20-yearly (crosses) 1-hour precipitation mean and variance observed in Seoul. Linear trend lines of yearly (solid line) and 20-yearly (dotted line) 1-hour precipitation mean and variance are shown together. 

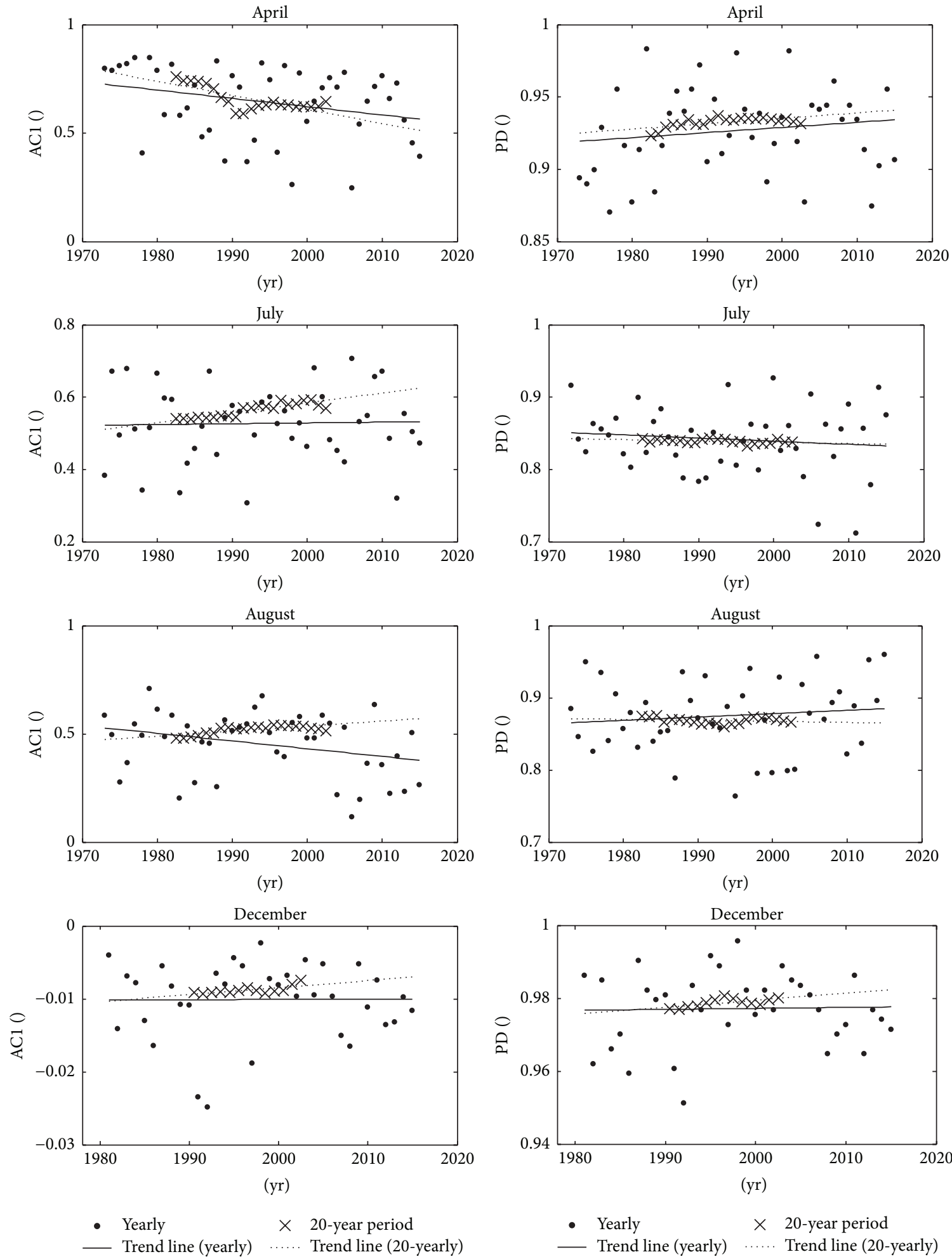

FIGURE 4: Temporal variation of yearly (dots) and 20-yearly (crosses) 1-hour precipitation lag-1 autocorrelation (AC1) and probability of dryness (PD) observed in Seoul. Linear trend lines of yearly (solid line) and 20-yearly (dotted line) 1-hour precipitation lag-1 autocorrelation and probability of dryness are shown together. 

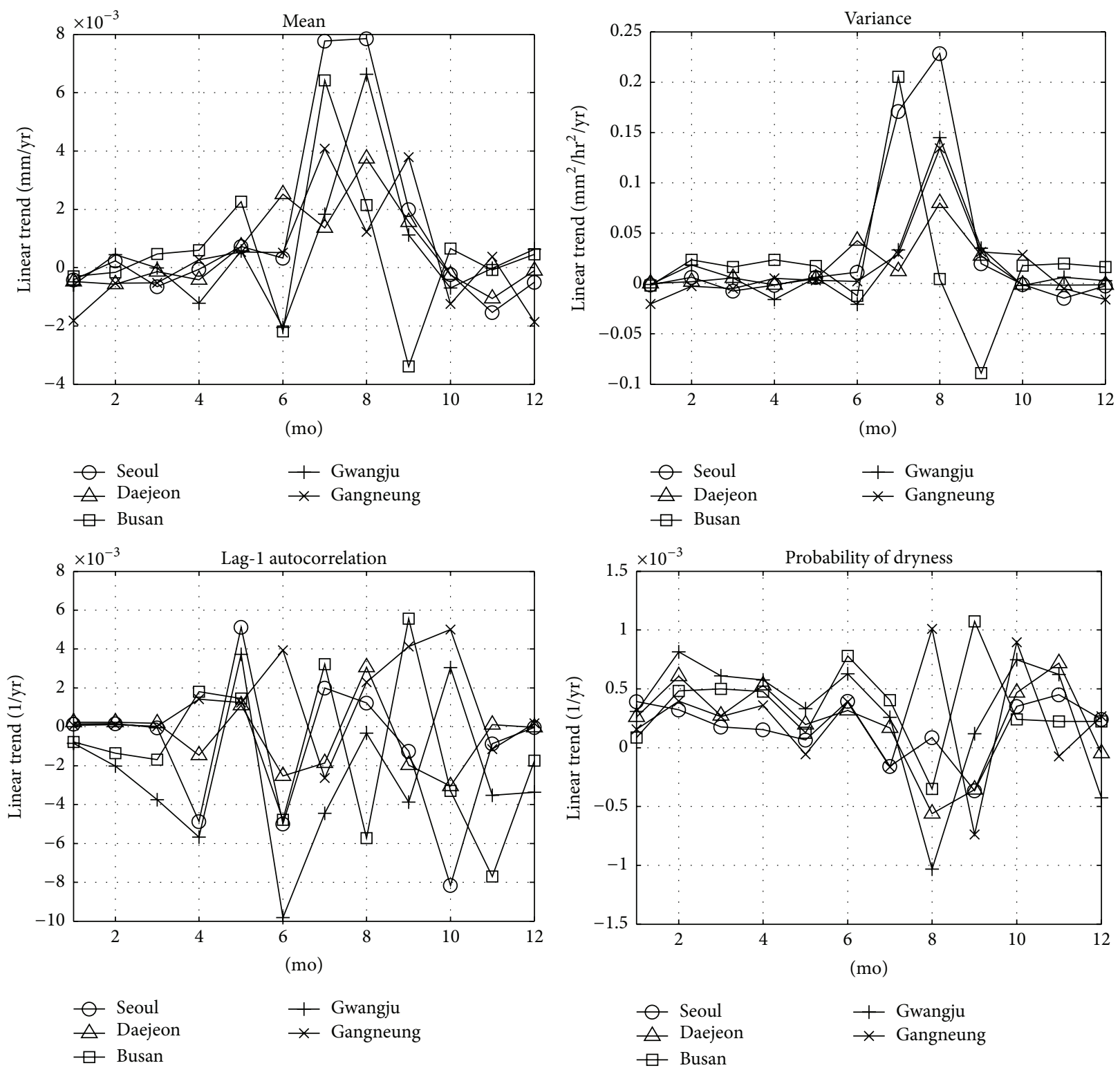

FIGURE 5: Seasonal variation of linear trend of 20-yearly 1-hour precipitation mean, variance, lag-1 autocorrelation, and probability of dryness of Korean Peninsula.

precipitation statistics with extreme event just as another relatively large but not extreme event. On the other hand, in case of the test based on 20-yearly precipitation statistics, one extreme precipitation event occurring in a given year influences twenty 20 -yearly statistics before being used in the Mann-Kendall test. Therefore, the magnitude of extreme event indirectly but clearly influences the Mann-Kendall test statistics.

3.3. Map of the Linear Trend of the Precipitation Statistics. Considering that the 5 major cities analyzed in Figure 5 are spatially well distributed across Korean Peninsula, the linear trend of each statistic will have interesting spatial characteristics especially for the months during which the vertical variability is large in Figure 5. Here, we present the analysis result for the months July and August during which the vertical variability (thus the spatial variability) of the linear trend of the precipitation statistics is particularly significant compared to the remaining months. The maps of the remaining months and the precipitation statistics are provided through the web application at the following web address: http://goo.gl/jSd0Gu.

Figure 7 shows the map of the linear trend of mean and PD of July 1-hour precipitation. The precipitation mean has an increasing trend for the most area except for the central and eastern coastal area of Korean Peninsula. The increasing trend of precipitation mean was clear for the northern and southern coastal area. The precipitation variance showed the similar spatial pattern as the precipitation mean. The probability of zero precipitation showed a decreasing trend for the northern 


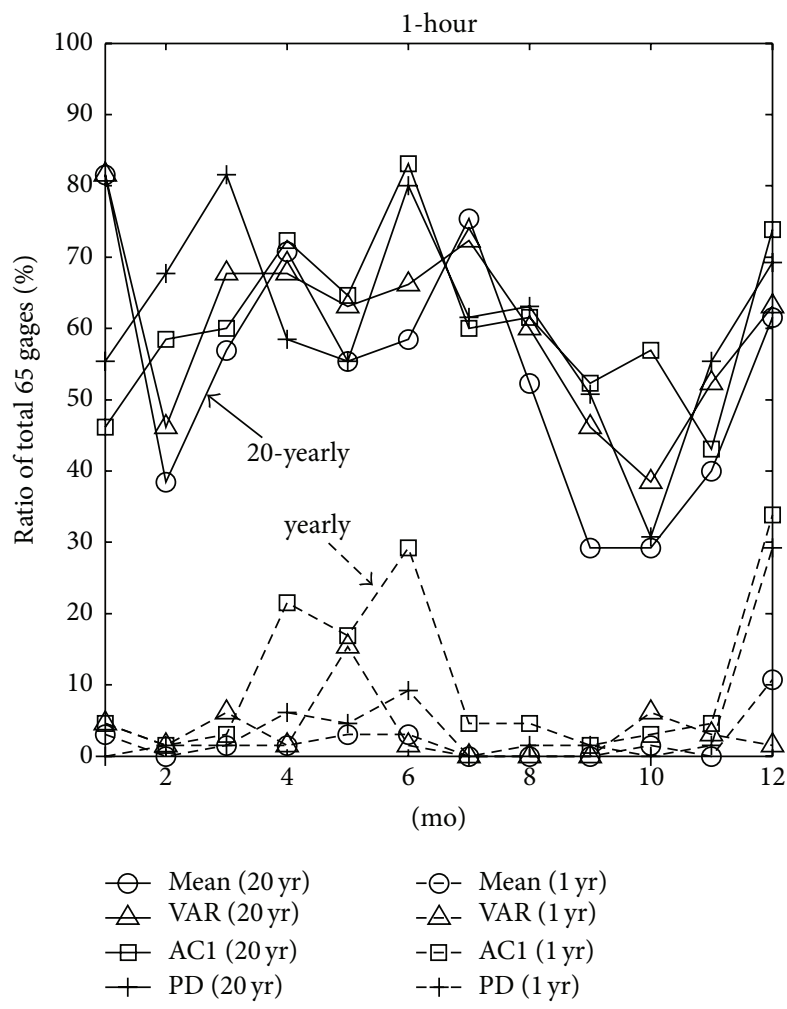

(a)

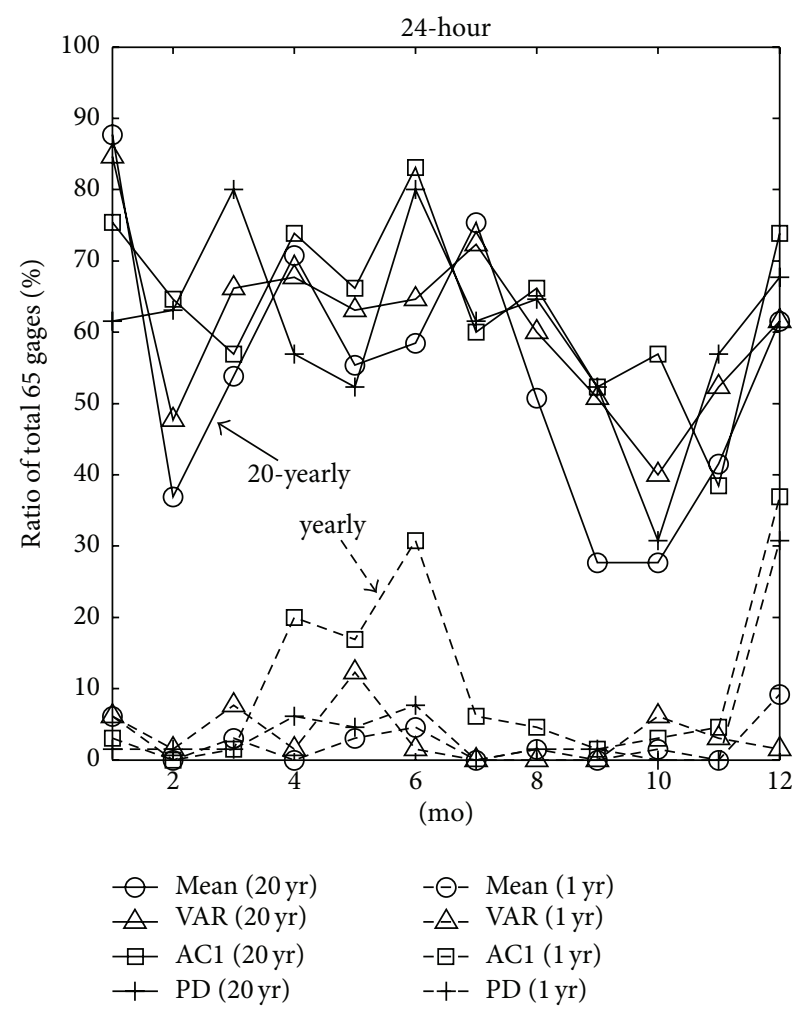

(b)

Figure 6: The result of the Mann-Kendall test on yearly and 20-yearly precipitation statistics. One-hour (a) and 24-hour (b) accumulation level are shown, respectively.

area and an increasing trend for the southern area. For the northern area, the precipitation mean has been increasing while the probability of dryness has been decreasing meaning that more precipitation has occurred over longer period of time compared to the past. For the southern area, both the precipitation mean and the probability of dryness have increased meaning that more precipitation has occurred over shorter period of time, which indicates the increase of danger of flash floods.

Figure 8 shows the map of the linear trend of mean and PD of July 24-hour precipitation. While the spatial pattern of precipitation mean is exactly the same as that of 1-hour precipitation, the linear trend of PD had negative value for the most part of the map including the southern coastal area at which PD of 1-hour precipitation has positive linear trend. This means that, at the southern coastal area, sporadic precipitation occurred more frequently at subdaily time scale. This finding is similar to that of Chung et al. [10] which suggested the northward shift of subtropical zone in Korean Peninsula by 70 to $120 \mathrm{~km}$. Due to this shift, it seems that southern part of Korea is experiencing frequent sporadic precipitation instead of the long-lasting and consistent precipitation caused by quasi-stationary polar front for the month of July.

Figure 9 shows the map of mean and PD of 1-hour precipitation of August. The mean precipitation had a positive linear trend for most part of Korean Peninsula. The PD showed a clear spatial variation having positive linear trend in north-to-central area and southeastern coastal area. The remaining part had a negative linear trend of $\mathrm{PD}$. This means that, compared to the past, the northern part of Korean Peninsula experienced higher amount of precipitation over shorter period of time and that the area starting from the southwestern coast toward the central part of Korean Peninsula experienced higher amount of precipitation over longer period of time and that the southeastern part of Korean Peninsula experienced lower amount of precipitation over shorter period of time. The spatial pattern of the linear trend of 24-hour precipitation of August was similar to that of 1-hour precipitation, which means that there is no dramatic change of temporal precipitation characteristics compared to the past. Considering that the August precipitation of Korean Peninsular is highly influenced by typhoons, this clear spatial variation of linear trend of precipitation mean and PD indicates that the spatial characteristics of typhoon landfall on Korean Peninsula have changed over the last 30 years. Kim et al. [28] indicated that this change of typhoon landfall characteristics is highly related to El Nino.

3.4. Linear Trend of Extreme Precipitation. This study performed the trend analysis on extreme precipitation values. For this purpose, the top-five yearly peak precipitation values at hourly and 24-hourly accumulation levels were chosen for each year of the study period. Then, the linear trend of their mean was evaluated. Figure 10 shows this result 

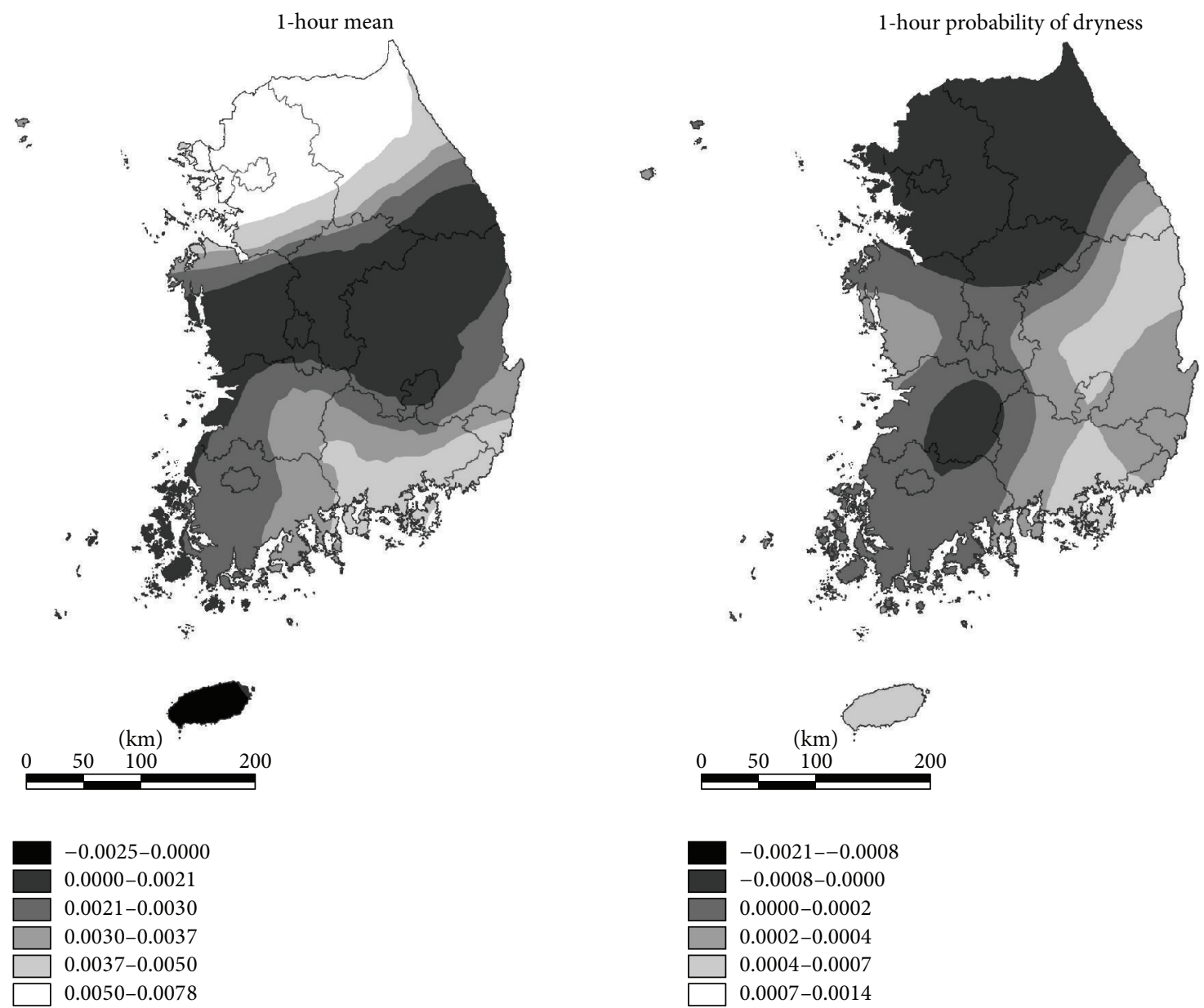

FIGURE 7: Map of the linear trend of 1-hour precipitation statistics of July.

corresponding to the hourly extreme precipitation observed at Seoul observation station.

The linear trend of both yearly and 20-yearly moving window mean of extreme precipitation is positive, which is similar to the result of the analysis performed on summer season precipitation data as shown in Figure 2. This result suggests that extreme precipitation as well as "usual" precipitation may have been influenced by climate change. This study repeated the trend analysis on the extreme precipitation for all 65 rain gages in the study area and performed the Mann-Kendall test. According to the test, mean of 1-hour and 24-hour extreme precipitation has statistically significant temporal trend at $25 \%$ and $11 \%$ among all gages, respectively. The ratio significantly increased for the 20 -year moving average values, which were $86 \%$ and $88 \%$ for 1 -hour and 24 -hour extreme precipitation, respectively. These ratios are greater than the ones corresponding to the entire summer precipitation time series shown in Figure 6, which suggests that the influence of climate change may have been greater for extreme precipitation than for the usual precipitation.

Figure 11 shows the map of the slope of the regression line relating year and the mean of the 1-hour and 24-hour extreme precipitation values. In the map, the whiter the area, the greater the increase of the extreme precipitation over the last
35 years. The spatial pattern is similar to the one corresponding to the usual precipitation of August shown in Figure 8, which suggests that the extreme precipitation of Korea tends to occur during the month of August significantly affecting the statistics of the entire August precipitation time series. No area in the map has negative linear trend meaning that the extreme precipitation has generally increased across Korean Peninsula. In addition, the gradual variation of shadings in the map indicates that there is a strong spatial tendency in the linear trend of extreme precipitation.

\section{Discussion}

4.1. Characteristic Scale of Precipitation Linear Trend. The linear trend of precipitation statistics has a smooth spatial variation as shown in Figures 7-9. Figure 12 shows the sample variogram (black dots), the averages of the sample variogram with a given interval (black squares), and the model variogram (black solid line) of each precipitation statistic that were used to create the maps of linear trend of June, July, August, and September. In each plot, the sample variogram values (black dots in each plot) do not have a large vertical variation and the interval variogram values have regular trend (starting from a low value, increasing with the distance, and 

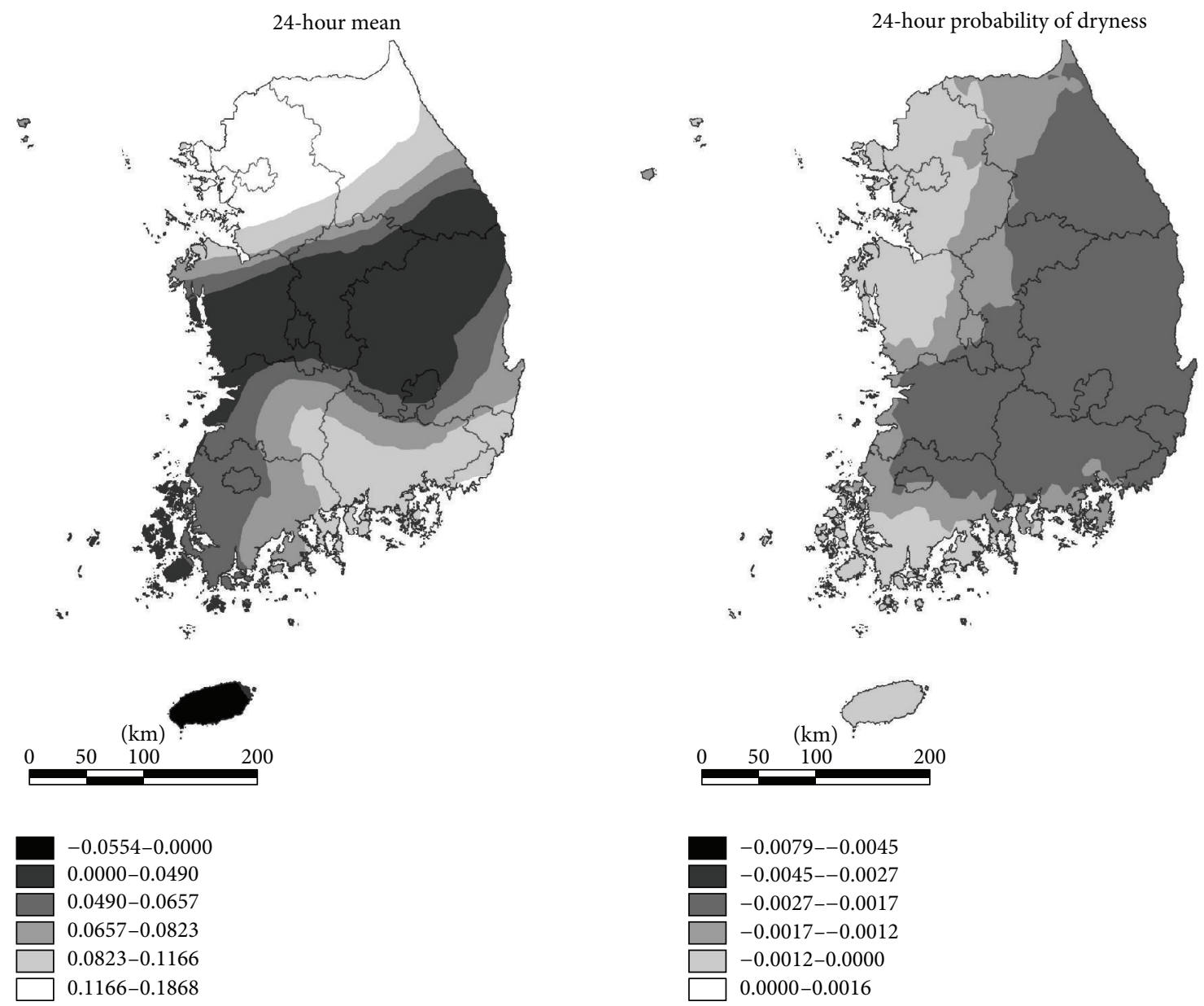

FIGURE 8: Map of the linear trend of 24-hour precipitation statistics of July.

then converging to a given value after a given distance) meaning that the linear trend has a strong spatial tendency.

Figure 13 shows the monthly variation of the model variogram range of the linear trend of each precipitation statistic. The linear trend of precipitation statistics estimated at one spatial location is not likely to influence those of other locations exceeding this range. The range of hourly statistics ranged between $10 \mathrm{~km}$ and $250 \mathrm{~km}$ depending on the type of statistics and the calendar month. The range of daily statistics was greater than that of hourly statistics ranging between $50 \mathrm{~km}$ and $570 \mathrm{~km}$. These range values are significantly lower than what was found in the study performed in China [15] which suggested that the linear trend of precipitation mean is associated with the shift of the synoptic-scale atmospheric circulation. Considering that the precipitation of Korean Peninsula is strongly influenced by orography, this finding suggests that the spatial tendency of the linear trend of precipitation of Korean Peninsula has not only the synopticscale variability influenced by the shift of the atmospheric circulation but also the mesoscale variability influenced by orography.

Figure 14 shows the monthly variation of the average of the variogram range values of the four different types of precipitation statistics (mean, variance, $\mathrm{ACl}$, and $\mathrm{PD}$ ).
Considering that the linear trend of the precipitation statistics is a strong indicator of the strength of climate change, the variogram range values shown here can be considered as an approximate characteristic scale of the strength of the climate change reflected upon precipitation in Korean Peninsula. Only within these distance ranges does the impact of climate change of one location tend to influence that of the other location. The variogram range value has a strong seasonal tendency having the greatest value during May and the low values during summer seasons (June through August). This seasonal variance seems to be associated with the fact that the dominant precipitation generation mechanisms of each season of Korean Peninsula are different, and the impact of climate change on each of the precipitation generation mechanisms is different.

4.2. Influence of One Single Extreme Event. While the pure interpretation about the analysis result based on the 20-yearly precipitation statistics is that the long-term precipitation characteristics of Korean Peninsula have changed over the last 30 years, there can be different views regarding the reason why the rejection percentage of the Mann-Kendall test drastically changes depending on the size of the moving window. 

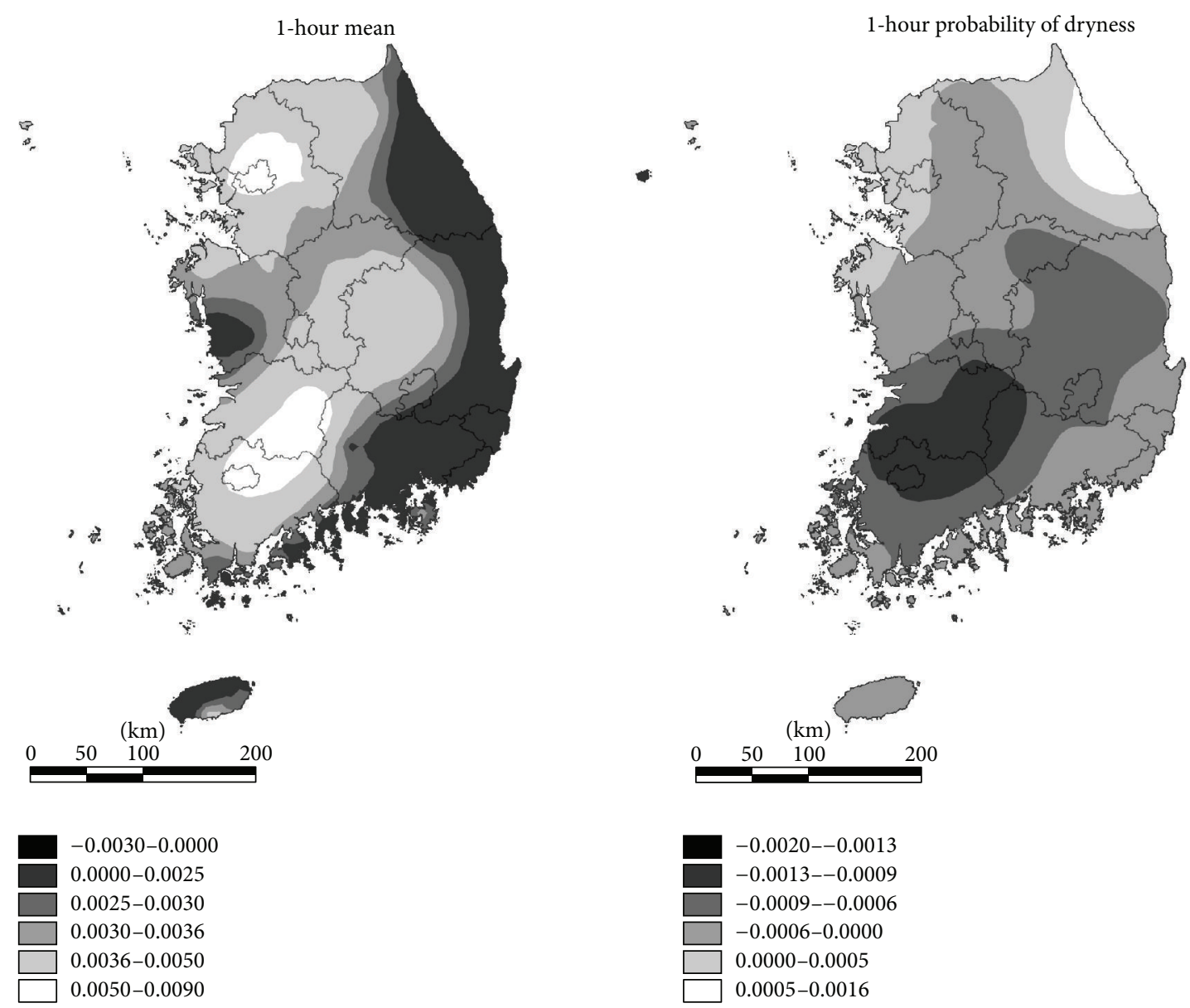

FIgURE 9: Map of the linear trend of 1-hour precipitation statistics of August.

One view is that one extreme yearly statistic that is influenced by an extreme precipitation or drought event in the time series affects twenty 20-yearly statistics, which subsequently affects the Mann-Kendall statistics. While the occurrence of the extreme event of which magnitude is significantly greater than those occurring in the past can be a strong indicator of the climate change, it is hasty to conclude that the long-term precipitation characteristics have changed because of one single extreme event even though the test result indicates so. Figure 15 shows the same test result on the 20yearly precipitation statistics, but this time the greatest yearly precipitation mean was removed from the time series. In the same plot, the test result of the original Mann-Kendall test is also shown. The rejection percentage does not change significantly from the original case. This comparison indicates that the temporal trend of the long-term precipitation statistics suggested by this study is not governed by one single extreme event but reflects the overall precipitation characteristics observed at the gage locations.

\section{Conclusion}

This study analyzed the spatial variability of the linear trend of the various statistics of the precipitation observed in Korean
Peninsula during the period between 1981 and 2012. The major conclusions of this study are as follows:

(1) While the yearly precipitation statistics do not show temporal trend based on the Mann-Kendall test, the long-term precipitation statistics with the moving window size of 20 years showed the statistically significant temporal trend at $28 \%$ to $88 \%$ of all 65 rain gages depending on the types of the precipitation statistics and the calendar month. This observationbased result suggests that there has been the impact of climate change in Korean Peninsula.

(2) The linear trend of the precipitation statistics was more apparent during the summer months (June through September) than it is during the other seasons in Korean Peninsula. For the summer months, precipitation mean and variance had a positive linear trend for most part of Korean Peninsula, and the linear trend of the probability of dryness varied across the Korean Peninsula having positive or negative values. This result indicates that the Korean Peninsula experienced the change of the temporal pattern of precipitation and this change varies by location. 


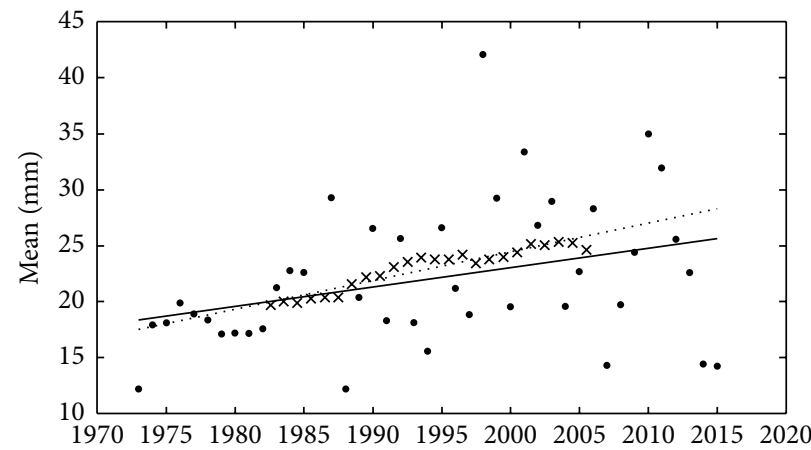

(yr)

$$
\begin{aligned}
& \text { - Yearly } \times 20 \text {-yearly } \\
& \text { - } y=0.1743 x-325 \quad \text { …. } y=0.2554 x-486
\end{aligned}
$$

Figure 10: Time series of the mean of the top-five 1-hour yearly peak precipitation observed at Seoul observation station. Dots are the yearly mean values, and crosses are the 20-year moving window mean values. Solid and dotted lines are the least square fit linear regression line of the yearly and 20-yearly mean values, respectively.

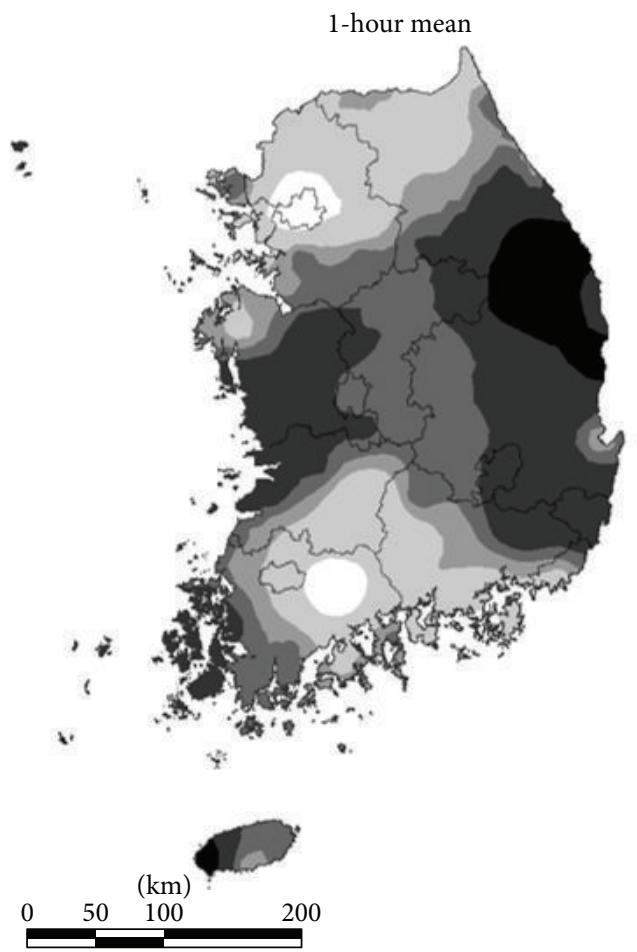

$0.0000-0.0396$

$0.0396-0.0809$

$0.0809-0.0984$

0.0984-0.1159

$0.1159-0.1572$

$0.1572-0.2554$

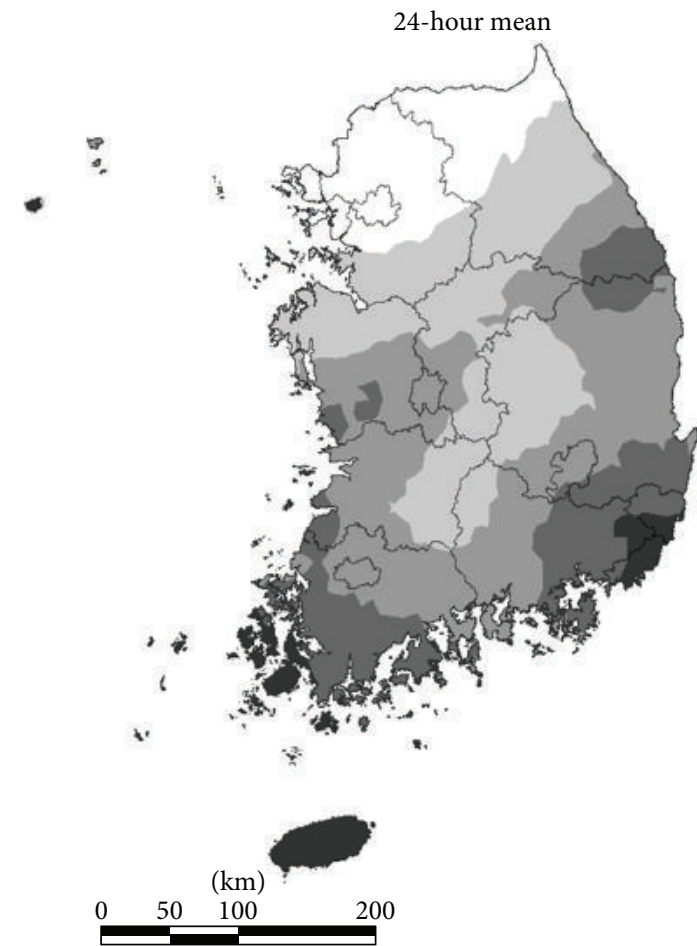

0.0000-0.1095

$0.1095-0.1985$

$0.1985-0.2334$

$0.2334-0.2660$

$0.2660-0.3477$

0.3477-0.6006

(a)

(b)

FIGURE 11: Map of the linear trend of (a) 1-hour and (b) 24-hour extreme precipitation. 

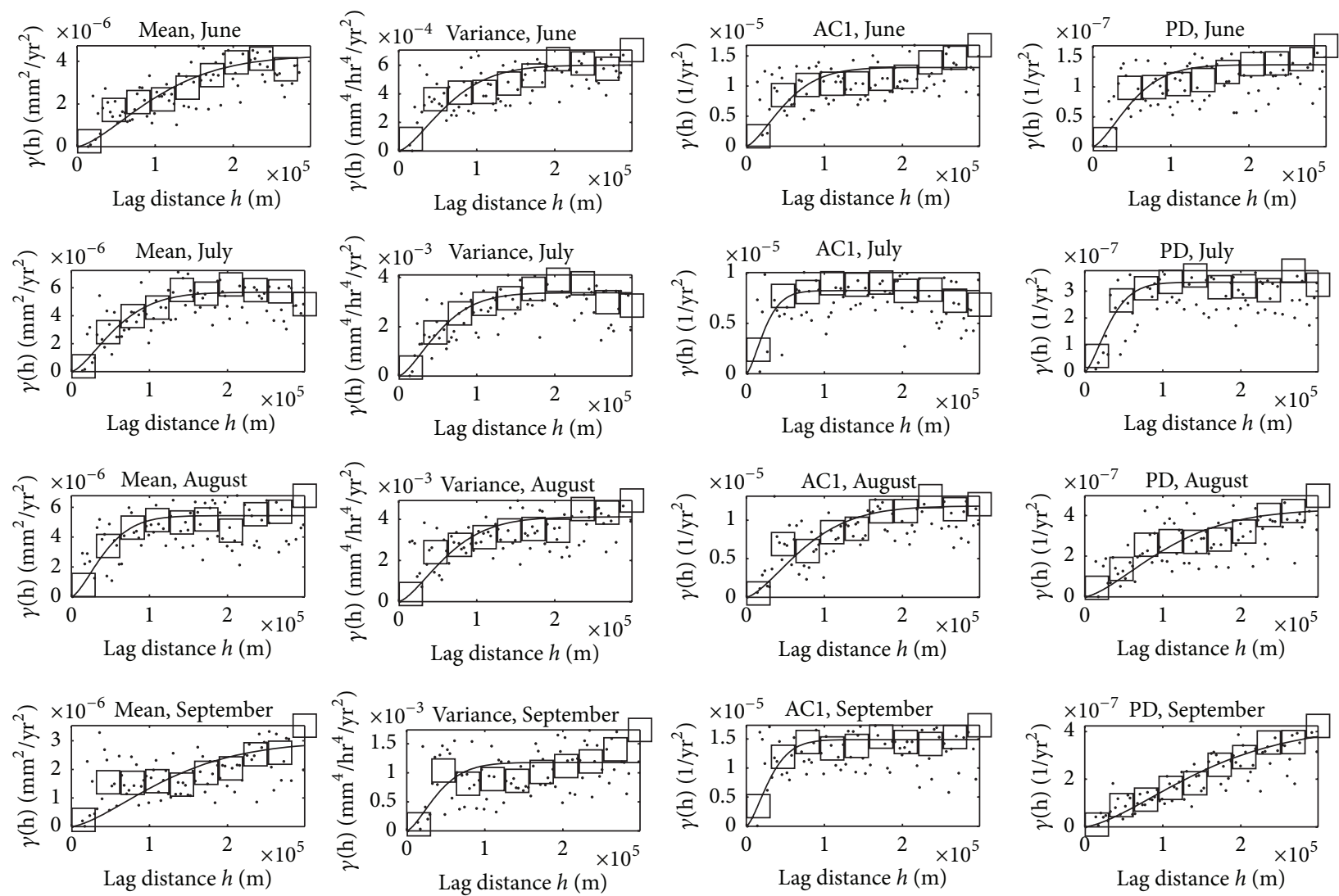

FIGURE 12: The sample variogram (black dots), the moving averages of the sample variogram (black squares), and the model variogram (black solid line) of the linear trend of the precipitation statistics of June, July, August, and September.

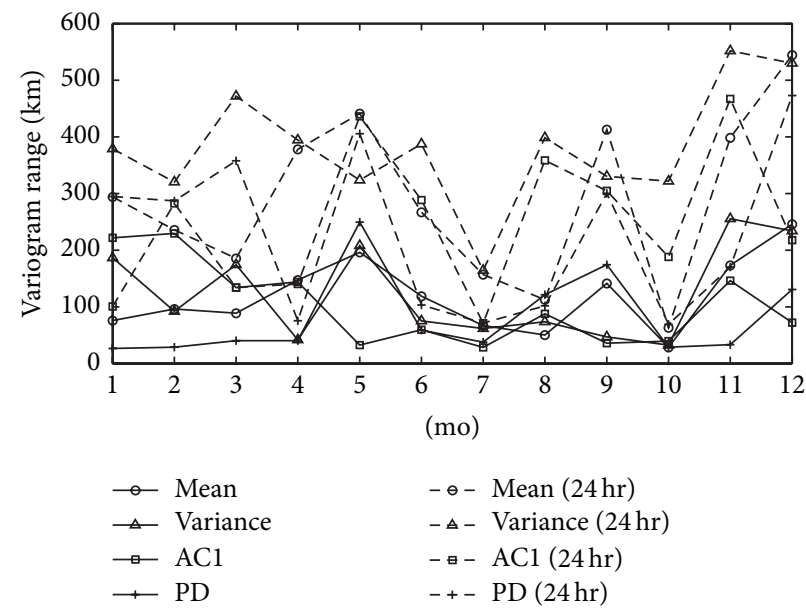

FIGURE 13: Monthly variation of the model variogram range of the precipitation mean, variance, AC1, and PD of hourly and daily precipitation of Korean Peninsula.

(3) The linear trend of the precipitation statistics had a strong spatial tendency showing smooth variation over Korean Peninsula. The variogram analysis revealed that the characteristic scale of linear trend of hourly and daily precipitation statistics ranges between $50 \mathrm{~km}$ and $200 \mathrm{~km}$ and between $100 \mathrm{~km}$ and $250 \mathrm{~km}$, respectively. This characteristic scale is significantly lower than the one caused by the shift of atmospheric circulation due to climate change. This means that the linear trend of precipitation and thus the impact of the climate change reflected upon precipitation in Korean Peninsula are influenced not only 


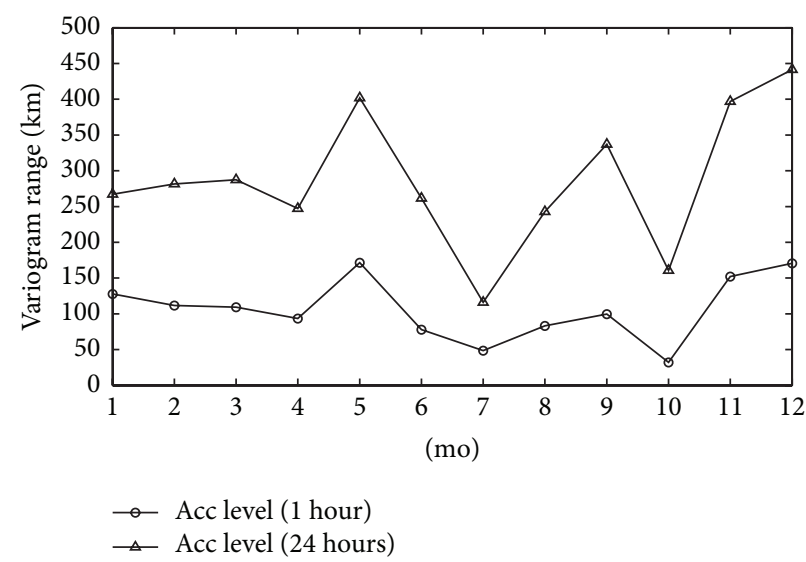

FIgURE 14: Characteristic scale of climate change reflected upon precipitation linear trend in Korean Peninsula.
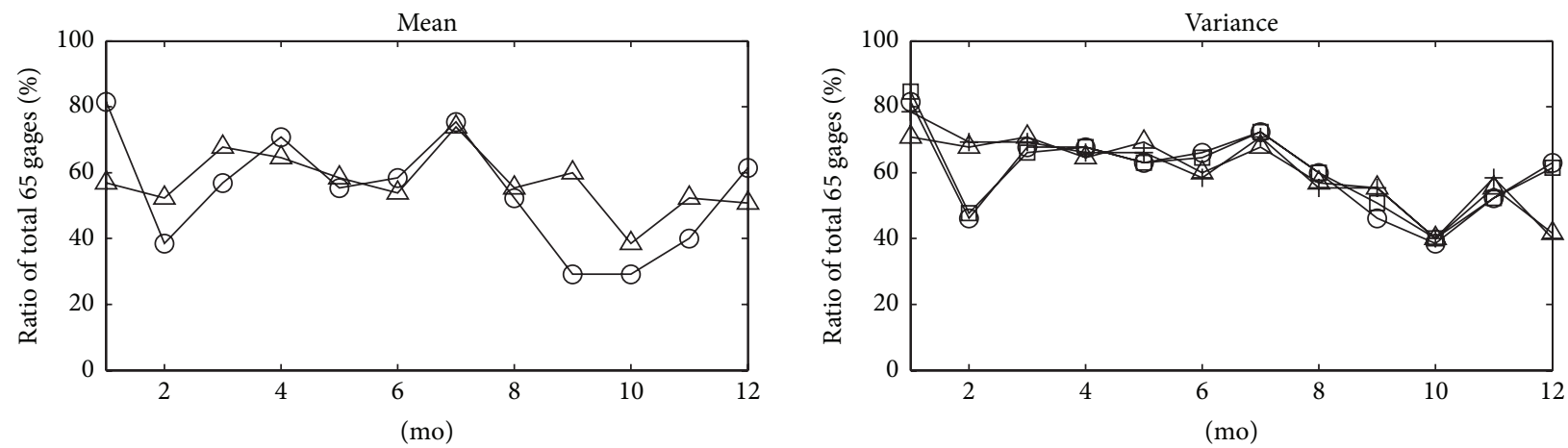

- Original (1 hour)

$\triangle$ Max removed (1 hour)

$\square$ Original (24 hours)

+ Max removed (24 hours)

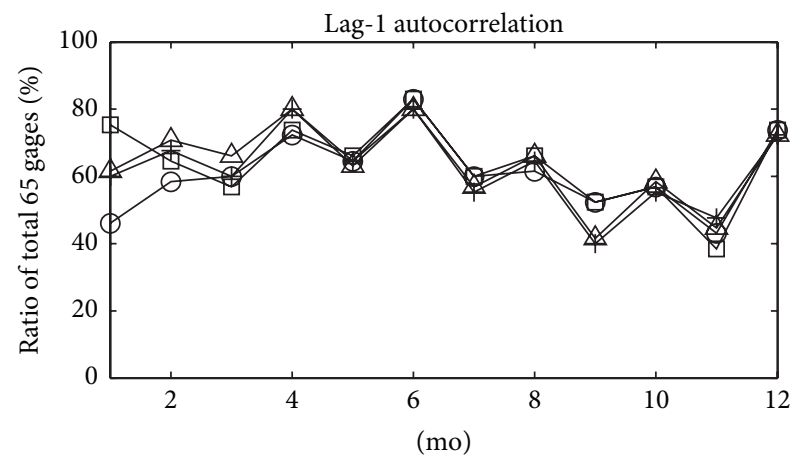

$$
\begin{aligned}
& - \text { Original (1 hour) } \\
& \triangle \text { Max removed (1 hour) } \\
& \square-\text { Original (24 hours) } \\
& + \text { Max removed ( } 24 \text { hours) }
\end{aligned}
$$

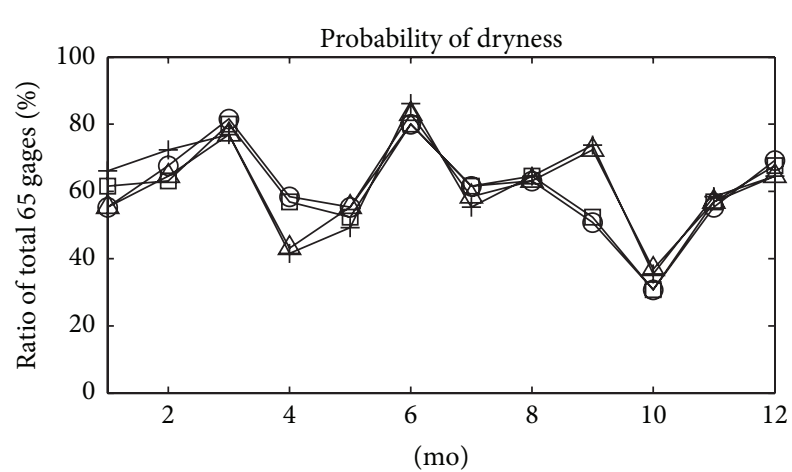

- Original (1 hour)

$\triangle$ Max removed (1 hour)

$\square$ Original (24 hours)

+ Max removed (24 hours)

$$
\begin{aligned}
& \bigcirc \text { Original (1 hour) } \\
& \triangle \text { Max removed (1 hour) } \\
& \square \text { Original (24 hours) } \\
& + \text { Max removed (24 hours) }
\end{aligned}
$$

FIGURE 15: Comparison of the Mann-Kendall test rejection rates among 65 gages before and after removing the greatest yearly precipitation mean.

by the shift of the atmospheric circulation but also by the other factors of precipitation generation mechanisms at small scale such as orography. This result suggests that the future plans of water resources management of Korean Peninsula should consider this mesoscale variability of precipitation linear trend that otherwise can be missed if the plan is based only on the GCM simulation result which mainly reflects the synoptic-scale variability due to shift of the atmospheric circulation. 


\section{Competing Interests}

The authors declare that they have no competing interests.

\section{Acknowledgments}

This research was supported by the Basic Research Laboratory Program through the National Research Foundation of Korea (NRF) funded by the Ministry of Science, ICT \& Future Planning (Grant ID: NRF-2015041523).

\section{References}

[1] NRC, Advancing the Science of Climate Change, Exit EPA Disclaimer National Research Council. The National Academies Press, Washington, Wash, USA, 2010.

[2] T. F. Stocker and C. C. Raible, "Climate change: water cycle shifts gear," Nature, vol. 434, no. 7035, pp. 830-833, 2005.

[3] IPCC (Intergovernmental Panel on Climate Change), Climate Change 2013: The Physical Science Basis, Intergovernmental Panel on Climate Change, Geneva, Switzerland, 2013.

[4] Y. S. Chung and M. B. Yoon, "Interpretation of recent temperature and recipitational trends observed in Korea," Theoretical and Applied Climatology, vol. 67, no. 3-4, pp. 171-180, 2000.

[5] J. H. Kim, C. H. Ho, M. H. Lee, J. H. Jeong, and D. Chen, "Large increase in heavy rainfall associated with tropical cyclone landfalls in Korea after the late 1970s," Geophysical Research Letters, vol. 33, no. 18, Article ID L18706, 2006.

[6] Z.-Z. Hu, "Interdecadal variability of summer climate over East Asia and its association with $500 \mathrm{hPa}$ height and global sea surface temperature," Journal of Geophysical Research Atmospheres, vol. 102, no. 16, pp. 19403-19412, 1997.

[7] C.-P. Chang, Y. Zhang, and T. Li, "Interannual and interdecadal variations of the East Asian summer monsoon and tropical Pacific SSTs. Part I: roles of the subtropical ridge," Journal of Climate, vol. 13, no. 24, pp. 4310-4325, 2000.

[8] R. Wu and B. Wang, "A contrast of the East Asian summer monsoon-ENSO relationship between 1962-77 and 1978-93," Journal of Climate, vol. 15, no. 22, pp. 3266-3279, 2002.

[9] C.-H. Ho, J.-H. Kim, K.-M. Lau, K.-M. Kim, D. Gong, and Y.-B. Lee, "Interdecadal changes in heavy rainfall in China during the northern summer," Terrestrial, Atmospheric and Oceanic Sciences, vol. 16, no. 5, pp. 1163-1176, 2005.

[10] Y.-S. Chung, M.-B. Yoon, and H.-S. Kim, "On climate variations and changes observed in South Korea," Climatic Change, vol. 66, no. 1-2, pp. 151-161, 2004.

[11] C.-H. Ho, J.-Y. Lee, M.-H. Ahn, and H.-S. Lee, "A sudden change in summer rainfall characteristics in Korea during the late 1970s," International Journal of Climatology, vol. 23, no. 1, pp. 117-128, 2003.

[12] C. Kim, M.-S. Suh, and K.-O. Hong, "Bayesian changepoint analysis of the annual maximum of daily and subdaily precipitation over South Korea," Journal of Climate, vol. 22, no. 24, pp. 6741-6757, 2009.

[13] T. J. Osborn, M. Hulme, P. D. Jones, and T. A. Basnett, "Observed trends in the daily intensity of United Kingdom precipitation," International Journal of Climatology, vol. 20, no. 4, pp. 347-364, 2000.

[14] C. Frei and C. Schär, "Detection probability of trends in rare events: theory and application to heavy precipitation in the
Alpine region," Journal of Climate, vol. 14, no. 7, pp. 1568-1584, 2001.

[15] Y. Wang and L. Zhou, "Observed trends in extreme precipitation events in China during 1961-2001 and the associated changes in large-scale circulation," Geophysical Research Letters, vol. 32, no. 9, pp. 1-4, 2005.

[16] M. Brunetti, L. Buffoni, M. Maugeri, and T. Nanni, "Precipitation intensity trends in northern Italy," International Journal of Climatology, vol. 20, no. 9, pp. 1017-1031, 2000.

[17] H. Chang and W.-T. Kwon, "Spatial variations of summer precipitation trends in South Korea, 1973-2005," Environmental Research Letters, vol. 2, no. 4, Article ID 045012, 2007.

[18] K. E. Kunkel, D. R. Easterling, D. A. R. Kristovich, B. Gleason, L. Stoecker, and R. Smith, "Meteorological causes of the secular variations in observed extreme precipitation events for the conterminous United States," Journal of Hydrometeorology, vol. 13, no. 3, pp. 1131-1141, 2012.

[19] S. S. Roy and M. Rouault, "Spatial patterns of seasonal scale trends in extreme hourly precipitation in South Africa," Applied Geography, vol. 39, pp. 151-157, 2013.

[20] R. S. Bradley, H. F. Diaz, J. K. Eischeid, P. D. Jones, P. M. Kelly, and C. M. Goodess, "Precipitation fluctuations over Northern Hemisphere land areas since the mid-19th century," Science, vol. 237, no. 4811, pp. 171-175, 1987.

[21] H. F. Diaz, R. S. Bradley, and J. K. Eischeid, "Precipitation fluctuations over global land areas since the late 1800's," Journal of Geophysical Research, vol. 94, no. 1, pp. 1195-1210, 1989.

[22] M. Hulme, T. J. Osborn, and T. C. Johns, "Precipitation sensitivity to global warming: comparison of observations with $\mathrm{Had}$ CM2 simulations," Geophysical Research Letters, vol. 25, no. 17, pp. 3379-3382, 1998.

[23] P. Maheras, "Changes in precipitation conditions in the western Mediterranean over the last century," Journal of Climatology, vol. 8, no. 2, pp. 179-189, 1988.

[24] B. Yu and D. T. Neil, "Long-term variations in regional rainfall in the south-west of Western Australia and the difference between average and high intensity rainfalls," International Journal of Climatology, vol. 13, no. 1, pp. 77-88, 1993.

[25] C. Rodríguez-Puebla and S. Nieto, "Trends of precipitation over the Iberian Peninsula and the North Atlantic Oscillation under climate change conditions," International Journal of Climatology, vol. 30, no. 12, pp. 1807-1815, 2010.

[26] A. Longobardi and P. Villani, "Trend analysis of annual and seasonal rainfall time series in the Mediterranean area," International Journal of Climatology, vol. 30, no. 10, pp. 1538-1546, 2010.

[27] Y. Kim, M. Kim, E. Jeon, J. Lee, K. Min, and Y. Jang, "Polarization phenomenon of precipitation in the Korean Peninsula," Climate Research, vol. 5, no. 1, pp. 1-15, 2010.

[28] J.-S. Kim, S.-K. Yoon, S. M. Oh, and Y.-I. Moon, "Changes in typhoon activities and regional precipitation variability over the Korean Peninsula according to different phases of El Nino," Advances in Meteorology, vol. 2015, Article ID 983268, 8 pages, 2015. 

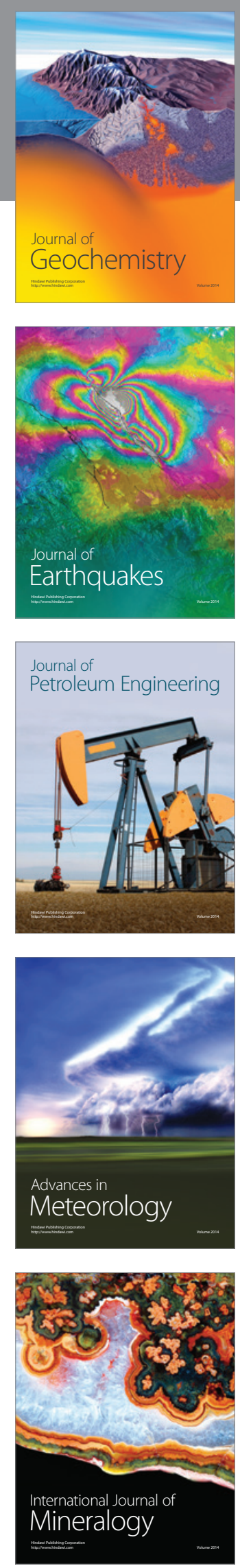
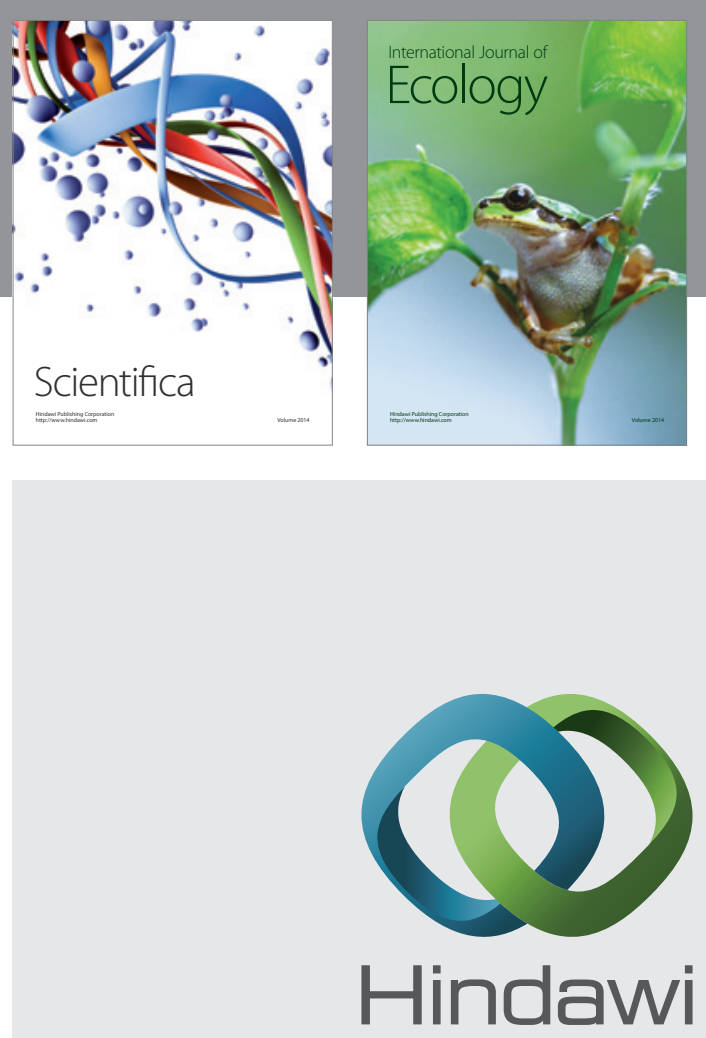

Submit your manuscripts at

http://www.hindawi.com
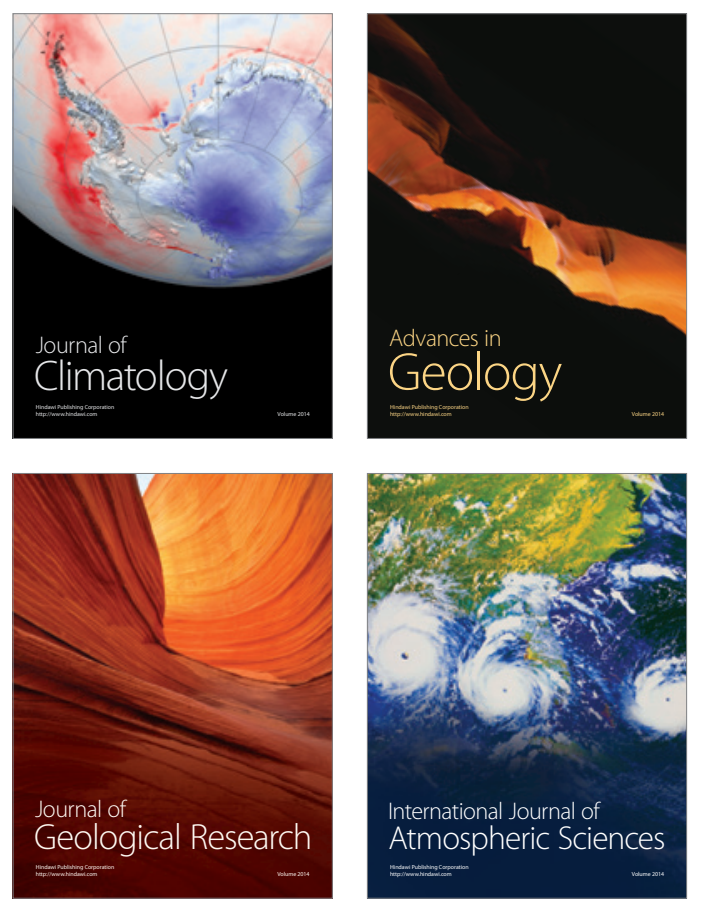

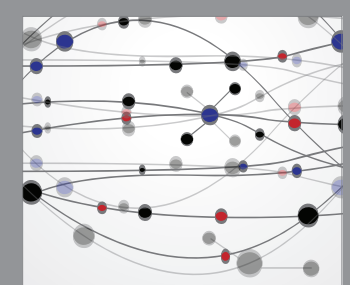

The Scientific

\section{World Journal}
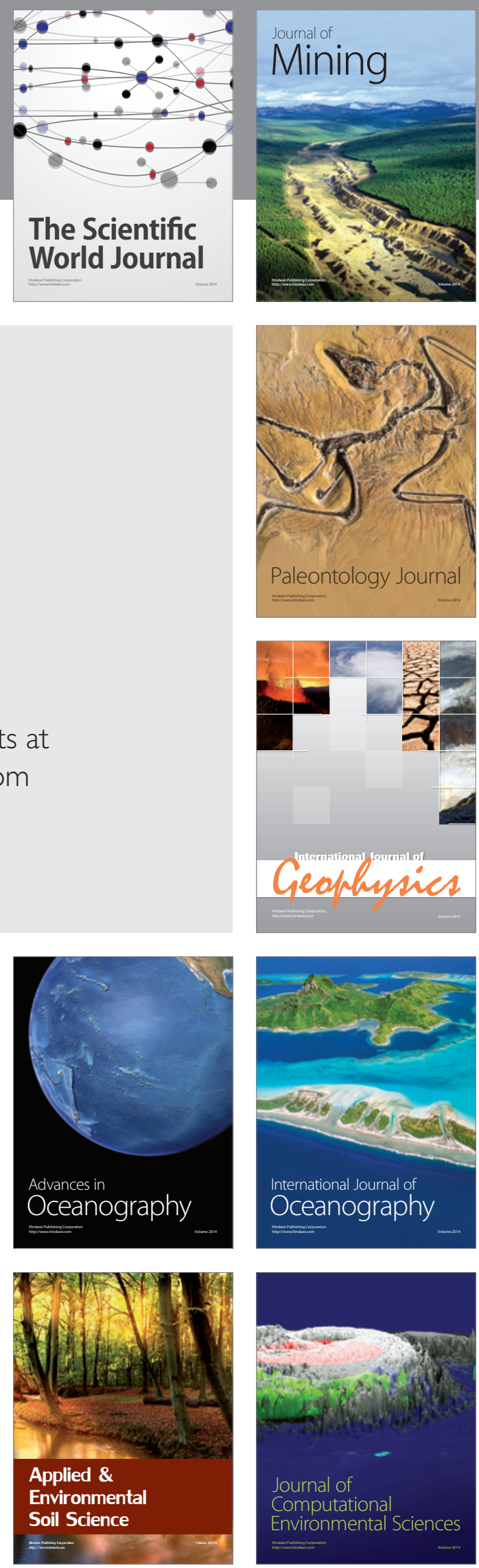